\title{
Hydrological regime alteration and ecological flow evaluation in mountain rivers
}

\author{
C. Dresti ${ }^{1}$, G. Becciu ${ }^{2}$, H. Saidi ${ }^{1}$ \& M. Ciampittiello ${ }^{1}$ \\ ${ }^{1}$ National Research Council, Institute of Ecosystem Study, Italy \\ ${ }^{2}$ Milan Polytechnic, Italy
}

\begin{abstract}
In the Alpine region, the hydropower production has caused alterations in the hydrological regime of most rivers, due to the massive withdrawal of water and to the construction of dams and reservoirs, which modify the natural flow duration curve of the river. These alterations may result in a decrease in hydromorphological and ecological quality of the river and limitations are considered, usually expressed as an ecological flow that has to be guaranteed. Many types of approaches are suggested in literature to define this flow, taking into account hydrological, physical, chemical and biological factors. Methods based only on hydraulic/hydrological parameters are often preferred, due to simplicity and robustness. More, with methods based only on hydrological parameters is simpler to take into account changes in river regime due to anthropic activities. However, some ecological issues are also important for river quality, such as the lentic-lotic characteristics of flow, but they are difficult to be expressed in crisp numerical values. In the last years more complex methods have been proposed as an alternative to hydrological models. One of them is the method CARAVAGGIO (Core Assessment of River hAbitat VAlue and hydro-morpholoGIcal cOndition). Although this model is able to take into account a great number of different aspects, its application is not always possible due to the difficulties in entering the river in some sites. In this paper a procedure able to merge the ease of use of hydrological methods and the multi-factor approach of CARAVAGGIO is proposed. Ecological flow is estimated from basic hydrological information, using a simple set of coefficients to take into account other quality issues, particularly
\end{abstract}


the lentic-lotic features of flow regime. Application to a case study in the Province of Verbano-Cusio-Ossola, in the north-western part of Piedmont Region in Italy, is presented.

Keywords: water resources management, river regime alterations, ecological flow, lentic-lotic characteristics.

\section{Introduction}

In the Alpine region, the hydropower production is an extremely important source of energy [1]. Already in 1998, Gleick [2] estimated that at the time almost $500,000 \mathrm{~km}^{2}$ of land were inundated worldwide by reservoirs. In Switzerland, Austria and the North of Italy, most of the rivers are dammed [3]. Dams can heavily modify the natural flow duration curve of the river. In particular, they modify the timing, the frequency and the duration of high and low flows. Consequently, they also alter the rates at which rivers rise and fall during rainfall events [4]. Richter and Thomas [4] highlight how large hydropower dams are able to capture high water flows and store them for later use, and this can result in lowered flood peaks and rapidly fluctuating hydrologic pattern in the downstream river, in correspondence to alternating periods of power generation. In many cases, water releases can be much lower than natural levels, during periods when reservoir levels are being restored.

All these situations can causes many environmental problems and disturbances to mountain river systems $[5,6]$, such as loss of aquatic habitats, extinction of fish populations, deterioration of landscapes [3]. Several studies [7-9] have shown that the alterations of flow regime is the most serious and continuing threat to ecological sustainability of rivers. Bunn and Arthington [10], and later Poff and Zimmerman [11], have analysed the consequences of altered flow regimes on ecosystems and aquatic biodiversity and highlight that sometimes it's difficult to determine which attributes of the altered flow regime are directly responsible for the impacts on ecosystems, due to a lag effect in biological response to flow alteration. Nevertheless, it's fundamental for river managers to recognise that many aspects of flow regime are important for some ecological processes. Furthermore, in the future water resources managers will have to face greater challenges, since the global distribution of freshwater resources is altered by climate change $[12,13]$.

In this context, it's evident that various factors determine the health of a river ecosystem [14], such as river flow, water quality, physical structure of the channel and the riparian zone and the presence of physical barriers to connectivity [15]. Among this factors, hydro-morphology has an important role, since it's strongly influenced by river flow, which can change the erosion - transport dynamics, and has strong influence on river ecology [16].

For these reasons, the definition of an ecological flow, i.e. a human modified flow regime that captures the natural flow variability in order to maintain the structure and the functional integrity of the aquatic ecosystem [17], is fundamental in order to manage water resources efficiently. 
The aim of this paper is the estimation of the optimal ecological flow that should be released from water intakes structures, in a mountain river, taking into account the hydro-morphological state and the lentic-lotic characteristics of the stream, which are very important for river ecosystem and in particular for macroinvertebrates [13].

\section{Methods}

\subsection{Hydro-morphology}

The flow regime alterations in mountain areas may modify the stream hydromorphology [18] and this can cause irreversible alterations in water circulation [19]. The Water Framework Directive of the European Union [20] requires member states to achieve 'Good Status' in all surface and ground waters. 'Good Status' is a combination of 'Good Chemical Status' and 'Good Ecological Status', which is based on four elements, i.e. macro-invertebrates, macrophytes, fish and phytobenthos. Furthermore, it includes supporting elements affecting the biological status, such as channel forms and water depth. In this context, it's fundamental to evaluate the physical habitat contribution to biodiversity conservation, in terms of 'good ecological quality' in rivers, and the 'hydromorphological' component of this quality [21].

In this study, the evaluation of the hydro-morphological state was carried out using the method CARAVAGGIO (Core Assessment of River hAbitat VAlue and hydro-morpholoGical cOndition) [22]. This method is very useful to collect a great amount of information for the description of river habitats, linked to hydromorphological conditions of the river. Each application of the method consists in two stages: i) a field survey, during which it's necessary to register some hydromorphological and hydrological features of the stream, filling in a field sheet; ii) an analysis with a software, in order to obtain some quality synthesis indexes. In the first stage, basic morphological channel features are registered on a selected $500 \mathrm{~m}$ segment along the longitudinal axis of the river. Morphological channel characteristics, as well as the type of flow, the type of the material in the riverbed, the channel and bank modifications, the type of vegetation, and the land use, are evaluated in ten sections, placed every $50 \mathrm{~m}$ within the research area. Furthermore, a synthetic description of the entire site is required and includes some morphological forms and alterations such as the shape of the valley, the presence and number of riffles and pools, bars and sedimentation/erosion areas.

Data obtained from the field survey can be introduced in the CARAVAGGIO software, in order to evaluate three synthesis indexes: i) HQA (Habitat Quality Assessment), which evaluates the river habitat diversification and quality, that are linked to the global quality of the site; ii) HMS (Habitat Modification Score), which quantifies the morphological alteration of the site; iii) LRD (Lentic-lotic River Descriptor), which characterizes the site in terms of lentic-lotic features. A detailed description of these indexes can be found in [23].

In particular, HQA depends on the type of flow, the type of substratum, the presence of deposition or erosion areas and the type of vegetation in the channel 
and banks; HMS depends on the reinforcement of river banks, the presence of dams, weirs, etc., the artificial substratum of the river, the presence of bridges and culverts; LRD depends on the width of the section, the depth of the water, the substratum of the river, the type of hydrological regime.

In order to evaluate the hydro-morphological quality, HQA and HMQ can be expressed in terms of Ecological Quality Ratio (EQR) [20, 23], expressed in equations (1) and (2):

$$
\mathrm{EQR}_{\mathrm{HQA}}=\frac{\mathrm{HQA}-11}{54-11}
$$

in which 54 is the median value for HQA in the Alpine region and 11 is the minimum value.

$$
\mathrm{EQR}_{\mathrm{HMS}}=\frac{100-\mathrm{HMS}}{100}
$$

in which 100 is the maximum value possible for HMS.

It's possible to define 5 classes for each index, shown in tables 1 and 2:

Table 1: Quality classes using the index HMS.

\begin{tabular}{|c|c|}
\hline EQR $_{\text {HMS }}$ & Quality \\
\hline$\geq 0.94$ & High \\
\hline$\geq 0.82$ & Good \\
\hline$\geq 0.58$ & Moderate \\
\hline$\geq 0.28$ & Poor \\
\hline$<0.28$ & Bad \\
\hline
\end{tabular}

Table 2: Quality classes using the index HQA.

\begin{tabular}{|c|c|}
\hline EQR $_{\mathrm{HQA}}$ & Quality \\
\hline$\geq 0.84$ & High \\
\hline$\geq 0.63$ & Good \\
\hline$\geq 0.42$ & Moderate \\
\hline$\geq 0.21$ & Poor \\
\hline$<0.21$ & Bad \\
\hline
\end{tabular}

A Global Hydro-morphological Index (GHI) can be evaluated, as shown in equation (3):

$$
\mathrm{GHI}=\frac{\mathrm{EQR}_{\mathrm{HMS}}-\mathrm{EQR}_{\mathrm{HQA}}}{2}
$$

The Water Framework Directive [20] states that the 'Good Ecological Status' should be reached; so only three classes were considered (table 3 ).

Since LRD index is strictly linked to river flow and hydraulic features, its use was considered for the evaluation of optimal ecological flow. 
Table 3: Quality classes using the index GHI.

\begin{tabular}{|c|c|}
\hline GHI & Quality \\
\hline$\geq 0.85$ & High \\
\hline$\geq 0.63$ and $<0.85$ & Good \\
\hline$<0.63$ & Non-sufficient \\
\hline
\end{tabular}

\subsection{Ecological flow}

The ecological flow of a river segment can be defined as the stream flow which is able specified features of the ecosystem [24]. Its assessment should take into account hydrological, ecological, geomorphological and anthropic factors. In 2004, Acreman and Dunbar [15] reviewed the methods used worldwide to evaluate this flow and highlight that they can be divided in four categories: i) look-up tables; ii) desktop analysis; iii) functional analysis; iv) hydraulic habitat modelling. The most commonly applied methods are based on simple indices given in look-up tables, in particular hydrologically-defined indices, which make the flow depend on the mean flow or exceedance percentiles from a flow duration curve. However, these methods don't take into account any of the ecological and hydro-morphological issues, important for river management.

In order to combine the simplicity of hydrological methods with ecological factors, a mixed approach is here suggested. For this aim, the simple approach defined by the regional legislation of the North of Italy [25] was considered. With this formulation, the ecological flow is defined as a percentage of the long-term mean annual flow. It's normal value is $10 \%$ of the long-term mean annual flow, but this value may be increased up to $20 \%$ by some coefficients (M, A, T), to take into account morphology and water quality.

A further coefficient, $Z$, is here suggested to take into account the hydromorphological features. This parameter is expressed as a function of two CARAVAGGIO indexes, GHI and LRD.

The modified version of the current formulation of ecological flow (EF), expressed in (1/s) is the following (equation 4$)$ :

$$
E F=K \cdot Q_{\text {med }} \cdot S \cdot M \cdot Z \cdot A \cdot T
$$

where:

- $\quad \mathrm{K}$ may vary from one region to another and its typical value is 0.1 ;

- $\quad Q_{\text {med }}$ is the mean annual flow;

- $\quad \mathrm{S}$ is the catchment area;

- $\quad$ M depends on the morphology of the macro-region;

- $\quad$ T depends on the seasonal variability of river flow;

- A depends on the exchange with groundwater;

The additional coefficient $\mathrm{Z}$ is expressed by the relationship in equation (5):

$$
Z=1+(1-G H I)^{\alpha}
$$

and

$$
\alpha=1-L R D^{*}
$$


LRD $^{*}$ is a normalized version of LRD and varies between 0 and 1 . It is evaluated as shown in equation (7).

$$
L R D^{*}=\frac{L R D-(-75)}{90-(-75)}
$$

in which -75 and 90 are considered respectively the limits for the parameter, indicating lotic conditions (negative values) and lentic conditions (positive values). In mountain rivers, negative values are expected to represent natural conditions.

The parameter $Z$ varies between 1 and 2, approaching 1 when the hydromorphological quality is high and 2 when hydro-morphological quality is poor. The rate with which these extreme values are approached depends on the lentic or lotic conditions of the streamflow, according to the parameter LRD*.

\section{Case study and results}

The study area is the Province of Verbano-Cusio-Ossola, situated in the southwestern Alps in Italy (figure 1). In this area, 38 applications of CARAVAGGIO method were carried out in 2013 in the catchment of river Toce and its main affluents, in addition to rivers San Bernardino, Cannobino, San Giovanni and Strona. In figure 1 the squares represent the applications of CARAVAGGIO method. The sites were chosen because of their position, in areas downstream from hydropower reservoirs, or in correspondence of big infrastructures, such as weirs, dams, bridges.

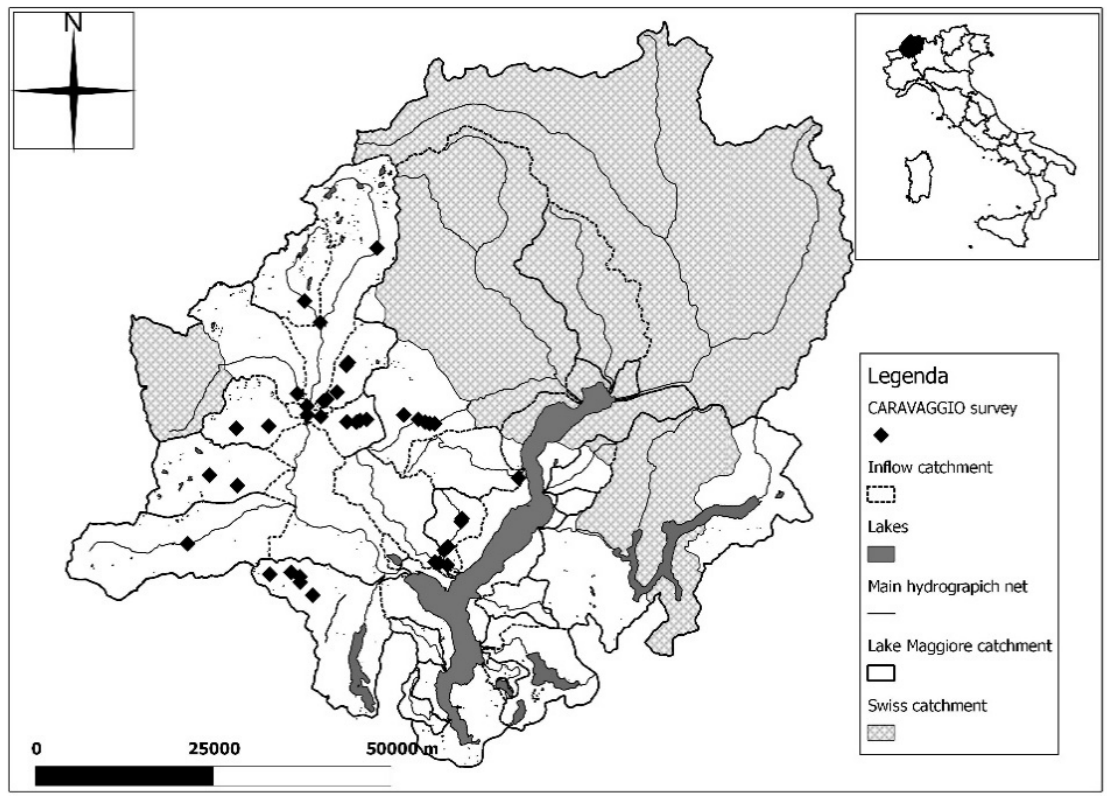

Figure 1: Study area and CARAVAGGIO applications. 
The results obtained from the application of CARAVAGGIO method in terms of GHI are shown in figure 2.

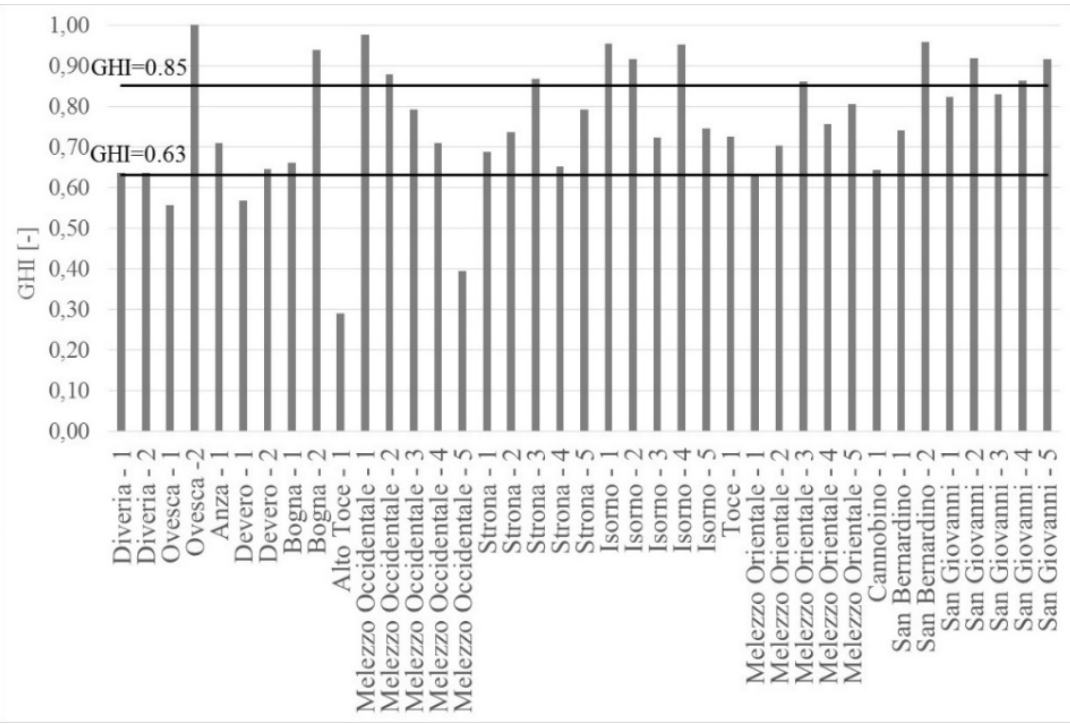

Figure 2: GHI values. The black lines represent the transition from not sufficient to good quality $(\mathrm{GHI}=0.63)$ and from good to high quality $(\mathrm{GHI}=0.85)$.

Looking at the results, it's clear that just four sites are characterized by a not sufficient hydro-morphological quality. Most of the sites (60\% of them) are in a good quality condition, which has to be maintained in time, according to the Water Framework Directive [20].

For this reason, the ecological flow with the formulation proposed has been evaluated just for the sites in bad or good conditions, and not in sites with high quality. In figure 3, it is possible to see how the parameter $\mathrm{Z}$ varies with $\mathrm{GHI}$ and different values of LRD*. The black squares represent the values of the parameter $\mathrm{Z}$ for the 38 sites analyzed.

The results show that for low values of $\mathrm{LRD}^{*}$, corresponding to lotic conditions (which can be considered natural in the mountain rivers analysed), the relationship between the parameter $\mathrm{Z}$ and GHI is almost linear. This means that when the stream is in lotic conditions, $Z$ values are proportional to hydro-morphological alterations. On the other hand, it's important to notice that $Z$ values are more than proportional to hydro-morphological alterations expressed by GHI index. In particular, when lentic features are extensive (high values of LRD*), which is the case of strong flow regime alterations due to reservoirs and water withdrawals, $Z$ values are less dependent on GHI values, that is on the degree of hydromorphological alterations. The behaviour of equation (5) has been chosen in order to take into account the need for higher river flows due to restore good conditions of oxygenation and water temperature. 


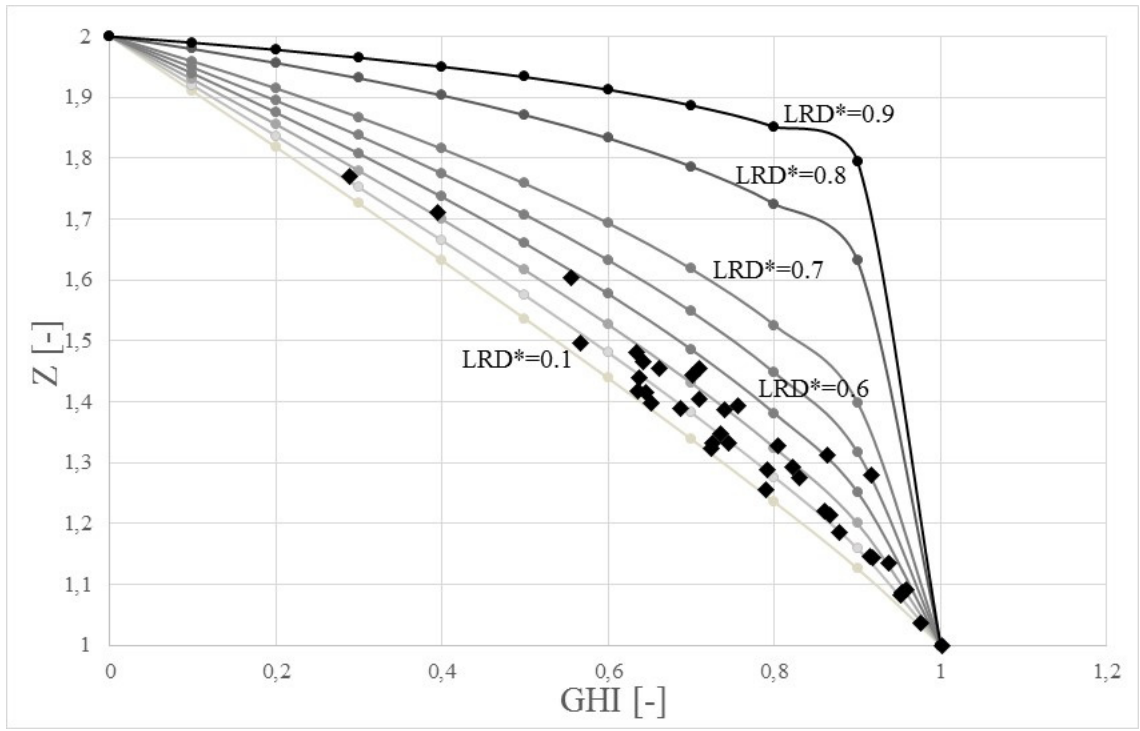

Figure 3: The parameter $\mathrm{Z}$ in function of GHI, evaluated for different values of LRD*. The black squares are the values of $Z$ evaluated for the 38 sites in which CARAVAGGIO was applied.

In figure 3 the black squares represent the values of $Z$ calculated for the 38 sites analysed. They vary in the range $1-1.77$, but all the sites are characterized by quite low values of LRD*. This means that in the Province the lentic-lotic features of the river have not been very altered by human impacts, even if the presence of hydro-power production is quite high. However, among these sites, just a few present very altered morphological features.

In table 4, it is possible to see the evaluation of EF for the sites considered.

It's possible to notice that in some cases the values of EF are much greater than the flow released during the day of the CARAVAGGIO application. In the case of the river Alto Toce - 1 it's $77 \%$ greater than the measured one. It's noticeable that this site has also a very low hydro-morphological quality, with $\mathrm{GHI}=0.29$. In one site of river Melezzo Occidentale, on the contrary, the ecological flow is just $26 \%$ higher than the measured discharge.

Considering the case of river Isorno, for which daily data are available, the results can be visualizes also on a flow duration curve of the considered section. In figure 4 there is an example, referring to river Isorno - 5. In light grey the discharge released downstream of the intake structure the day of CARAVAGGIO application is presented. The black line represent the ecological flow evaluated using the proposed parameter Z. It's possible to notice that in this way the ecological flow (which is $40 \%$ higher than the measured flow) is higher and corresponds to a different duration. 
Table 4: Environmental flow for the analysed sites.

\begin{tabular}{|c|c|c|c|}
\hline SITES & Flow $\left(\mathrm{m}^{3} / \mathrm{s}\right)$ & Z(-) & $\mathrm{EF}\left(\mathrm{m}^{3} / \mathrm{s}\right)$ \\
\hline Diveria - 1 & 2.15 & 1.42 & 3.05 \\
\hline Diveria - 2 & 1.48 & 1.44 & 2.13 \\
\hline Ovesca - 1 & 1.16 & 1.60 & 1.86 \\
\hline Anza - 1 & 1.08 & 1.45 & 1.57 \\
\hline Devero - 1 & 4.21 & 1.49 & 6.29 \\
\hline Devero - 2 & 4.96 & 1.42 & 7.02 \\
\hline Bogna - 1 & 0.59 & 1.45 & 0.86 \\
\hline Alto Toce - 1 & 1.74 & 1.77 & 3.08 \\
\hline Melezzo Occidentale - 3 & 0.92 & 1.26 & 1.15 \\
\hline Melezzo - 4 & 0.23 & 1.40 & 0.32 \\
\hline Melezzo Occidentale - 5 & 0.6 & 1.71 & 1.03 \\
\hline Strona - 1 & 0.32 & 1.39 & 0.44 \\
\hline Strona - 2 & 0.21 & 1.35 & 0.28 \\
\hline Strona - 4 & 1.97 & 1.40 & 2.75 \\
\hline Strona - 5 & 1.32 & 1.29 & 1.70 \\
\hline Isorno - 3 & 0.31 & 1.32 & 0.41 \\
\hline Isorno - 5 & 0.3 & 1.33 & 0.40 \\
\hline Toce -1 & 3.52 & 1.33 & 4.69 \\
\hline Melezzo Orientale - 1 & 0.56 & 1.48 & 0.83 \\
\hline Melezzo Orientale - 4 & 0.58 & 1.39 & 0.81 \\
\hline Melezzo Orientale - 5 & 0.3 & 1.33 & 0.40 \\
\hline Cannobino - 1 & 1.6 & 1.47 & 2.35 \\
\hline San Bernardino - 1 & 2.1 & 1.39 & 2.91 \\
\hline San Giovanni - 1 & 0.1 & 1.29 & 0.13 \\
\hline San Giovanni - 3 & 0.5 & 1.27 & 0.64 \\
\hline San Giovanni - 4 & 0.71 & 1.31 & 0.93 \\
\hline
\end{tabular}

\section{Conclusions}

The formulation proposed for ecological flow responds very well to a double necessity: on one side, the need to have a simplified approach, compatible with Italian regional planning regulation [25], and, on the other side, the need to take into account hydro-morphological quality linked to biological communities to be compliant with the requests of the Water Framework Directive [20]. To assess the effectiveness of the proposed approach, extensive field applications should be carried out. In particular, the improvement in ecological quality and the restoration of the river regime due to ecological flows should be tested in time, because the biological systems respond to external factors with a lag of time. 


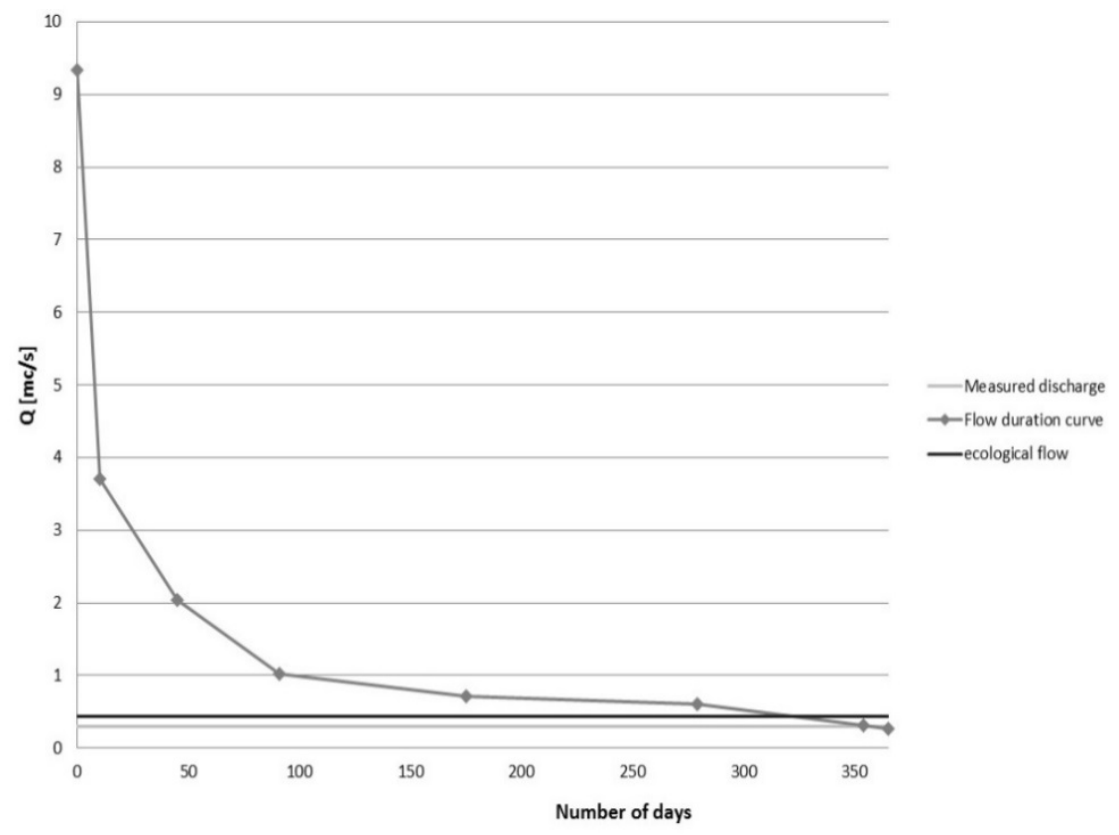

Figure 4: Flow duration curve and ecological flow for Isorno River - Pontetto.

\section{References}

[1] Fette, M., Weber, C., Peter, A., Wehrli, B., Hydropower production and river rehabilitation: A case study on an alpine river, Environmental Modeling \& Assessment, DOI 10.1007/s10666-006-9061-7, 2006.

[2] Gleick, P.H., The World's Water 1998-1999, Island Press: Washington DC, 1998.

[3] Truffer, B., Markand, J., Bratrich, C., \& Wehrli, B., Green electricity from Alpine hydropower plants, Mountain Research and Development, 21, pp. 19-24, 2001.

[4] Richter, B. D., \& Thomas, G. A., Restoring environmental flows by modifying dam operations, Ecology and Society, 12(1): 12, 2007.

[5] Truffer, B., Bratrich, C., Markard, J., Peter, A., Wueest, A., \& Wehrli, B., Green hydropower: The contribution of aquatic science research to the promotion of sustainable electricity. Aquatic Sciences, 65, pp. 99-110, 2003.

[6] WCD, Dams and Development. A new framework for decision making. The report of the World Commission on Dams. London: Earthscan, 2000.

[7] Naiman, R.J., Magnuson, J.J., McKnight, M., Stanford, J.A., The freshwater imperative: A research agenda. Island Press: Washington DC, 1995.

[8] Ward, J.V., Tockner K., Shiemer, F., Biodiversity of floodplain ecosystems: Ecotones and connectivity. Regulated Rivers: Research and Management, 11, pp. 125-139, 1999. 
[9] Lunqvist, J., Avert looming hydrocycle. Ambio, 27, pp. 428-433, 1998.

[10] Bunn, S.E., Arthington, A.H., Basic Principles and Ecological Consequences of Altered Flow Regimes for Aquatic Biodiversity. Environmental Management, 30 (4), pp. 492-507, 2002.

[11] Poff, N.L., \& Zimmerman, K.H., Ecological responses to altered flow regimes: a literature review to inform the science and management of environmental flows. Freshwater Biology, 55, pp. 194-205, 2010.

[12] Jackson, R.B., Carpenter, S.R., Dahm, C.N., McNight, D.M., Naiman, R.J., Postel, S.L., \& Running, S.W., Water in a changing world. Ecological Applications, 11, pp. 1027-1045, 2001.

[13] Dewson, Z.S., Alexander, B.W.J., \& Death, R.G., A review of the consequences of decreased flow for instream habitat and macroinvertebrates. Journal of North American Benthological Society, 26(3), pp. 401-415, 2007.

[14] Norris, R.H., \& Thoms, M.C., What is river health? Freshwater Biology, 41, pp. 197-209, 1999.

[15] Acreman, M., \& Dunbar, M.J., Defining environmental river flow requirements - a review, Hydrology and Earth System Sciences, 8(5), pp. 861-876, 2004.

[16] Vaughan, I.P., Diamond, M., Gurnell, A.M., Hall, K.A., Jenkins, A., Milner, N.J., Naylor, L.A., Sear, D.A., Woodward, G., \& Ormerod, S.J., Integrating ecology with hydro-morphology: a priority for river science management. Aquatic Conservation: Marine and Freshwater Ecosystems, 19, pp. 113$125,2009$.

[17] Suen, J.P., Determining the Ecological Flow Regime for Existing Reservoir Operation, Water Resources Management, 25, pp. 817-835, 2011.

[18] Wohl, E., Human impacts to mountain streams. Geomorphology, 79, pp. 217-248, 2006.

[19] Bucala, A., Wiekaczka, L., Evaluation of the hydro-morphological state of mountain streams under the influence of contemporary human activity (Polish Carpathians). Environmental Earth and Sciences, 73, pp. 34513463, 2015.

[20] European Commission and Parliament, Directive 2000/60/EC of 20 December 2000 establishing a framework for community action in the field of water policy, European Parliament and Council, Luxembourg, 2000.

[21] Newson, M.D., \& Large, A.R.G., 'Natural' rivers, 'hydro-morphological quality' and river restoration: a challenging new agenda for applied fluvial geomorphology. Earth Surface Processes and Landforms, 31, pp. 16061624, 2006.

[22] Buffagni, A., Demartini, D., \& Terranova, L., Manuale di applicazione del metodo CARAVAGGIO - Guida al rilevamento e alla descrizione degli habitat fluviali. Monografie dell'Istituto di Ricerca Sulle Acque del CNR, Roma, 1/i, 312 pp, 2013.

[23] CNR IRSA, CNR ISE, ARPA Piemonte, Regione Sardegna, Guideline and field protocols for deriving hydro-morphological and habitat information. Deliverable Pd3, Project INHABIT - LIFE 08 ENV/IT/000413, 2011. 
34 Ravage of the Planet IV

[24] Tharme, R.E., A global perspective on environmental flow assessment: emerging trends in the development and application of environmental flow methodologies for rivers, River Research and Application, 19, pp. 397-441, 2003.

[25] Regione Piemonte, Piano di Tutela delle Acque, 2007. 